\title{
Review
}

\section{Stewart Clegg, Martin Harris, and Harro Höpfl (ed.): Managing Modernity - Beyond Bureaucracy? Oxford University Press, 201I}

Reviewed by: Eric Breit, Researcher, Work Research Institute, HiOA, Norway

ureaucracy continues to be a highly debated concept in the field of management and organization studies. This book takes the pulse on bureaucracy by asking the question of to which extent recent changes in public and private sector management have taken us, as the title suggests, "beyond bureaucracy?" In so doing, it provides an up-do-date picture of contemporary research on bureaucracy and the so-called "postbureaucratic turn" across a diverse range of contexts, as well as an outline of key debates in the field. Without spoiling too much, the book does not conclude in either/or terms but paints a picture of "paradox and contradiction" (p. 2), which suggests a perplexing view of contemporary bureaucracies, in both the public and private sector.

The anthology contains 13 chapters, not including a brief introduction from the three editors and a foreword by John Clarke. The chapters are structured around four key themes. The first theme addresses some fundamental distinctions between "old" and "new" bureaucracies, and in so doing deals distinctively with the post-bureaucratic turn. Paul du Gay, one of the most central interpreters of Max Weber and the bureaucratic archetype, starts it all off by questioning a general tendency in public management to ignore or downplay the bureaucratic ethos to act with a "spirit of formalistic capacity," that is, as impartial and impersonal with regard to the execution of public duties (Chapter 1). Harro Höpfl (Chapter 2) examines New Public Management (NPM) in relation to the question of bureaucratic responsibility, arguing that it raises the same issues of accountability as the traditional bureaucratic forms of public administration. For instance, responsibility for the implementation of public has become much more diffuse as relations between ministers and servants are increasingly mediated by ad hoc committees and special advisors.

The second theme focuses on the UK National Health Service as a specific context in which traditional bureaucracy is being impacted by post-bureaucratic (NPM) reforms. David A. Buchanan and Louise Fitzgerald (Chapter 3) show that the traditional bureaucracy has not been significantly impacted by changes such as outsourcing and agentification. Rather, these features contribute to the characteristic of "accessorized bureaucracy," which points to the impression of transformation rather than substantive change. Ewen Speed (Chapter 4) examines the "soft rhetorics" of choice in the health care provision. He shows that the change in rhetorics does not change the nature of the bureaucracy, as patient choice is practically constrained by the preferences of NHS (National Health Service) clinicians. Martin Harris (Chapter 5) examines bureaucratic challenges through the introduction of ICT (information and communication technology), in particular the National Programme for Information 
Technology. He argues that the vision of the digital government or e-government is conflicting with the power relations and values of the NHS, thus leading to conflict and resistance.

The third theme revolves around how interactivity, power, and structures of control are conditioned by different bureaucratic forms. Jannis Kallinakos (Chapter 6) focuses on social production and collaboration taking place in the context of new, web-based modes of working in the public sector. A key point he makes is that these new forms of electronic interaction challenge traditional bureaucratic forms because of the instability and temporality of such interactions. Alvesson and Kärreman (Chapter 7) focus on human resource management (HRM) practices in two private "knowledge-intensive" firms. They show different assumptions about organizational identities and motivational structure in the two firms: From "meritocracy" with an emphasis on rules and procedures of promotions to "sociocracy" in which technical qualifications are downplayed in favor of interpersonal skills. In such knowledge-intensive firms, they claim, the HRM practices have crucial impacts on the bureaucratic form and its practices. Stephen Ackroyd (Chapter 8) takes a broader historical perspective on the post-bureaucratic turn. In contrast to a common understanding of the turn as being a fairly recent happening, he highlights the long historical roots of fragmentation and disaggregation of traditional bureaucracies. In particular, he argues that the UK manufacturing sector has been in a long process of industrial decline due not to influences from its environment but to a lack of centralized direction found in the classic models of bureaucracy.

The fourth theme involves attempts to recapture and reframe the bureaucratic archetype in light of the preceding insights. Stewart Clegg (Chapter 9) suggests that contemporary bureaucracies are becoming increasingly hybrid. This process takes place through iterations between what he labels processes of decomposition (extended supply chains, outsourcing, electronic governance) and recomposition, which consists of new, ill-defined organizational forms (e.g., temporary projects). Such developments, he argues, challenges the usefulness of bureaucracy as a robust theoretical object. Mike Reed (Chapter 10) offers a different account of the hybrid nature of contemporary bureaucracies by focusing on control regimes. He challenges Manuel Castell's dismissal of bureaucracy as an outdated organizational form by emphasizing the growing importance of polyarchic governance systems, which combine centralized authority while maintaining devolved democracy. Finally, Hugh Willmott (Chapter 11) rethinks the bureaucratic archetype and its significance for late modernity by emphasizing that the most pressing challenges are ethical and political in nature, rather than technical. He provides a powerful analysis of how the bureaucratic ethos has been eroded and "hollowed out" and the impact this has had on community and child-care services in the United Kingdom.

In all, the book does very well in gathering scholarly contributions from different academic disciplines (sociology, political science, management, organization studies), and as a reader one really gets a feeling of the kinds of debates that are permeating the field. One of the most interesting features of the book, and which spans across several of the chapters, is the hybrid developments that seem to characterize the post-bureaucratic turn. Several of the contributions seem to challenge polarized views of the relationship between traditional and new bureaucracies and rather support the notion of some kind of layering or sedimentation, which suggests that the new bureaucracies complement rather than challenge or replace the traditional ones. Given its centrality among the 
chapters, this notion of hybridity could have been expanded more by the editors. And critical questions could have been asked about the relevance of the concept for understanding the changes in bureaucratic forms and features.

The chapters are generally well written, and it is for the most part easy to follow the line of argumentation, both in each chapter and in the structuring of the chapters. The chapters thus undoubtedly provide important material for researchers interested in the theoretical aspects of contemporary bureaucracy in its broadest sense. Yet, at times the book also appears to suffer from a lack of editing; for instance, the introduction does not sufficiently address and discuss the concept of bureaucracy as well as the broader social and organizational implications of the post-bureaucratic turn-given that they are central for many of the subsequent chapters. This would appear to render the book less accessible for students and researchers that are new to the field. That said, there are good reviews here and there in the chapters, but this could have been expanded and made accessible up-front. Also, for readers that are not native English speakers, the language is at times difficult to understand and could have been simplified.

More generally, the book suffers from a lack of perspective(s). Most notably, nearly all the chapters bear a distinctive Anglo-Saxon mark, and thus provide only a selected understanding of the characteristics of contemporary bureaucracies. The book is therefore embedded in a specific theoretical and political-institutional field with its own characteristics, but with these characteristics rarely being made explicit to the reader. The editors could also have expanded in more detail on how notions of bureaucracy (including post- and neo-bureaucracy) differ and intersect across different contexts, at least those touched upon in the chapters. For instance, Alvesson and Kärreman's chapter draws from a study of (private sector) consultancy work, while other chapters focus on the public sector and draw more explicitly on Weber's ideal type. Finally, the book could have attempted to unpack the question of how to actually manage (in) contemporary bureaucracies. This would have made the book even more accessible to the practical community-in both the public and private sector.

Overall, however, the book offers invaluable insights to discussions and understandings of contemporary bureaucracies and their (changing?) characteristics. The book is not only interesting and provocative, but also offers an entertaining read that would inspire many readers in the areas of organizational studies and public administrationand perhaps even a few "bureaucrats," however one understands the term. 